\title{
Learning Style Index: Analysis and Smartphone-based Implementation
}

\author{
Yuki Homma and Mohamed Hamada \\ Software Engineering Lab. \\ University of Aizu, Japan \\ s1250183@u-aizu.ac.jp, hamada@u-aizu.ac.jp
}

\begin{abstract}
Recently, research on remote system is attracting a lot of attention due to the outbreak of infectious disease in 2019. Especially in the field of education, many instructors must deliver a lecture through the internet. However, sometimes there lacks the mutual understanding between instructors and students. In this research, we propose a mobile application to analyze the learning styles for individual learners. It provides students a tool to identify their best learning style and an efficient learning method. It also helps teachers to create suitable lecture materials by indicating the learning tendencies of their classes.
\end{abstract}

\section{Introduction}

Since the outbreak of Covid-19 in 2019, our society is shifting toward the remote systems in various fields. Under this circumstance, in the field of education, elearning has recently attracted the attention of many educators. Teachers can provide online lectures and personalized materials for students through an e-learning system. In this platform, people do not need to meet faceto-face. In traditional classroom, students have a chance to experience the lecture content just one time. On the contrary, online classroom is able students to review the content and understand it [1]. We can also take lectures wherever we are as long as we bring our device. Mobile device is one of the important tools to realize the online learning. They have great potentials. First of all, they are excellent in portability. We can use it anywhere to communicate with each other. The usage rate of smartphone is increasing over time. Global smartphone penetration rate in 2019 is over 40\% [2], and it is going to continue to increase in the future. In Japan, $64.7 \%$ of people have a smartphone [3]. Smartphone is becoming an essential element in our society. With the increasing number of people using a mobile device, the demand for e-learning is expected to grow in the future [4]. Although it is a very useful tool for learning, some people struggle when they learn online since the format does not suit their own learning style.

The goal of this study is to develop a mobile system that finds the best learning style for individual learners. People will understand their tendency in terms of learning style. Our system is expected to help students with customized and efficient learning and also help teachers to make their lectures intriguing and meet the needs of students by making use of cloud technologies. We employ the Felder-Silverman Learning Style Model [5]. In the system, users answer 55 questions in 5 different fields (Process, Effect, Perception, Understand and Input). This questionnaire enables learners to find the best learning style in each field. The system is implemented on iOS devices. Therefore, we develop the system with Swift and Xcode. We also use Nifty Cloud mobile backend to share and analyze the answers of users.

In this study, we develop an LSI (Learning Style Index) mobile system that finds the most suitable learning style for individual students. The findings in this research will help students understand their learning styles and help teachers prepare appropriate materials that meet individual students' needs.

\section{Background}

In our system, we adopt the Felder-Silverman Learning Style Model. The model is composed of 4 dimensions of learning styles. The first is the "Process" dimension which indicates what type of process is used when learners acquire knowledge. This process is divided into two parts, Active and Reflective. The second is the "Perception" dimension, which shows preference of learners in terms of senses. The preference is divided into Sensory and Intuitive. The third is the "Input" dimension, which is about what kind of information is used in learning. This dimension is divided into Visual and Verbal. The fourth is the "Understanding" dimension, which indicates the way to see things in understanding. It is divided into Sequential and Global.

This model is widely used in the educational questionnaire system. The web-based questionnaire system created by Felder and Soloman is known as a most popular questionnaire using the model [6]. The questionnaire has been translated into a lot of languages, and many people around the world take the questionnaire. The reliability and validity of the questions has been verified by many researchers $[7,8,9,10]$.

However, Hamada pointed out that the questionnaire system of the Felder-Silverman Learning Style Model 
provides only two options as choices for each question [11]. In real life, however, people's choice will not be simply black and white. Therefore, they, instead, provided 5 options for a question and enabled users to choose among several alternatives in a fuzzy-like system. They also added a new dimension called "Effect" to the model. The dimension indicates the process for fundamental skills, such as management and relationship. In the other words, that measures how the students are affected. The ways people are affected may be divided into Social and Emotional categories. Social learners prefer discussions and social interaction. The learners are easily influenced by others. On the other hand, Emotional learners are affected by their emotions. The modern model was made for engineering students, while the enhanced model is more generalized.

\section{Methodology}

\subsection{Tools}

We developed this application for mobile devices, especially for iPhone [12]. The application software of iPhone runs on a mobile operating system called iOS. Therefore, we needed to implement this application with the tool Xcode and Swift. We also used a cloud server to share the data of students and analyze it.

\subsubsection{Xcode}

Xcode [13] is an integrated development environment made by Apple. It has a lot of powerful functions to develop applications for iOS devices. The main function of Xcode is an editor, compiler, and iOS simulator. Source code written in Swift is compiled by LLVM compiler on Xcode, and Xcode builds and runs it on iOS simulator. This development tool realizes the high-performance development of applications. In this research, we use Xcode 10.1.

\subsubsection{Swift}

Swift [14] is a powerful programming language created by Apple for the development of applications of iOS devices. The main feature of this programming language is "high performance". Swift works 2.6 times faster than Objective-C and 8.4 times faster than Python 2. This is the reason why we chose Swift over Objective-C to implement our application. In this research, we used Swift 4.2.

\subsubsection{NICLOUD mobile backend}

NIFCLOUD mobile backend is a mBaas (mobile backend as a Service) system. The system provides developers with SDK (Software Development Kit) to incorporate additional functions to applications. The system also enables us to develop our application without considering the backend server.

\subsection{System Overview}

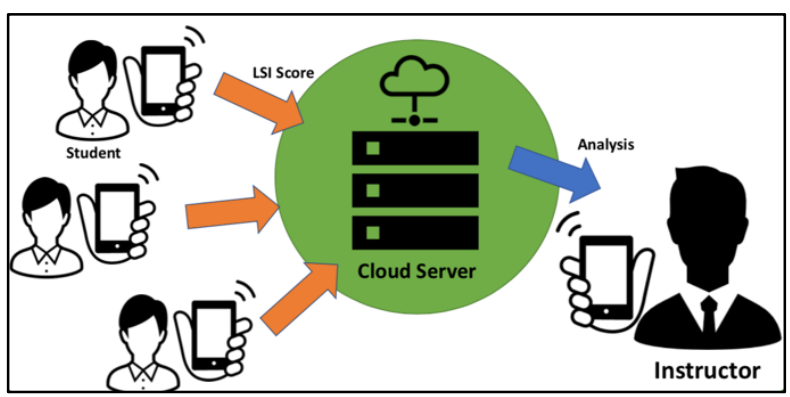

Fig. 1. System overview

Our mobile Learning Style Index application is implemented in Swift to be built on iOS devices on a client-side. The system uses a cloud server to store the data of students and analyze it. iOS devices exchange user data with a cloud server by just calling API on the clientside. The cloud server conducts member management and authentication. The function allows the application to provide individual data and analysis. Fig. 1 shows the layout of our system.

\subsection{Enhance Learning Style Index for Implementation}

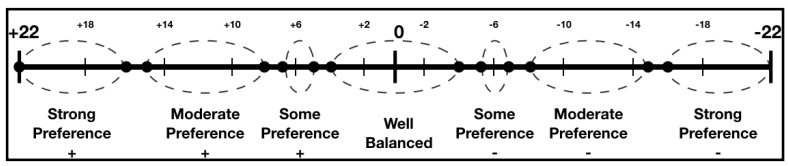

Fig. 2. Learning Style Index Used in this Study

Learning Style Index that was adapted from FelderSilverman Learning Style Model was used for implementation. Many researchers have utilized the modern Felder-Silverman model for online surveys analyzing the learning style. However, a problem with the model was that it only provides two options. Hassan and Hamada [15] improved the model to make it fit in the reallife setting. They made five options to answer each question. The enhanced model has been evaluated by them.

We applied this model to our questionnaire system. There are 11 questions for each dimension based on the learning model. Our questionnaire system consisted of 55 questions.

Each question had five options to choose from. If a user taps the 1st option, the score +2.0 is added to the user score. That means the point of learning style approaches plus preference by 2.0. If the user taps the 2 nd option, the score +1.0 is added to the user score. If the user taps the 3rd option, the score is not added to user score. If the user taps the 4th option, the score -1.0 is added to the user score. If the user taps the 5th option, the score -2.0 is added to the user score. Users repeat this process 55 times for the survey. The total score indicates the learning preference of the user.

The preference of the user for each dimension is classified into 7 groups. If the total score is between 4 and -4 , that indicates the user has a well-balanced preference in the dimension. If the total score is between 5 and 7 , or 
-5 and -7 , it shows the user has some preference. If the total score is between 8 and 15 , or -8 and -15 , this means the user has a moderate preference. If the total score is between 16 and 22 , or -16 and -22 , this signals the user has a strong preference. Figure 2 indicates the above classification of user preference.

\section{Results}

Our system is composed of 3 modules: Guest module, Student module, and Teacher module. Each module provides appropriate functions for the role of users. The purpose of this system is to analyze the members in a class and reveal the tendency of learning style in the class. Therefore, each module has to be divided by the system.

\subsection{Login function}
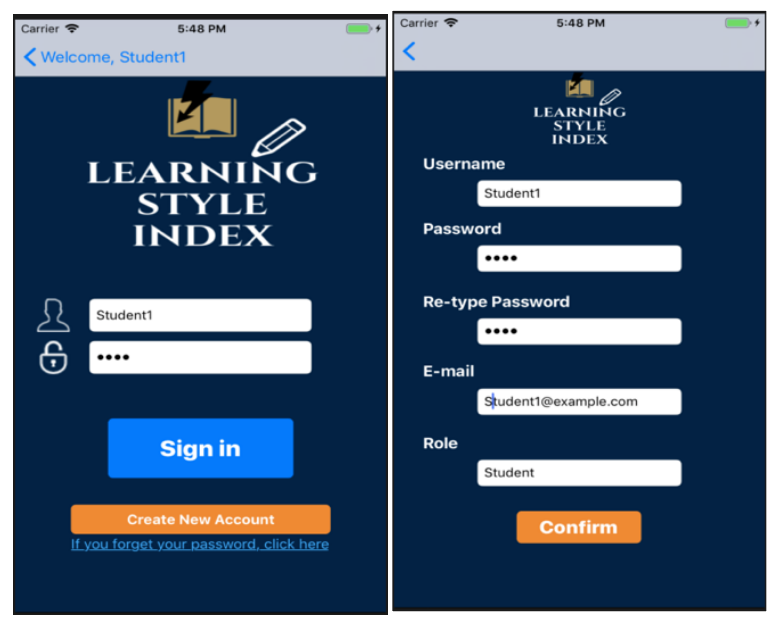

Fig. 3. The views for user authentication

We need to implement a function of user authentication to provide an appropriate module depending on the role of users. First, users must register information when they start using this application. This system needs the inputs of username, password, e-mail address, and role. Figure 3 shows the views when the user logs in to our system.

\subsection{Student Module}

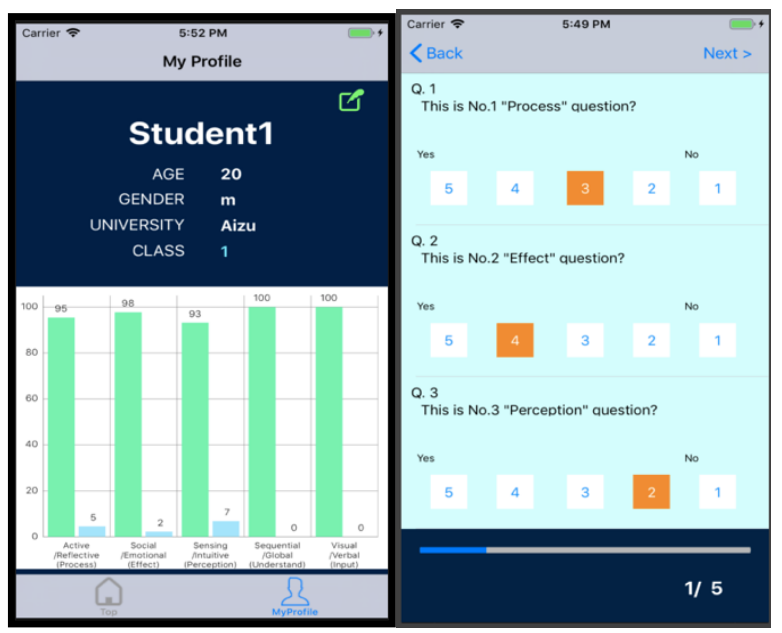

Fig. 4. The views of Student Module

The left side of Figure 4 is the view of the user profile when the user whose role is student logs in to our system. It displays the user information, such as name, age, gender, university, and classes which he takes. The view also shows the result of the LSI questionnaire in a bar chart. That enables us to make out the tendency of our learning style with ease.

The right side of Figure 4 is the view of our questionnaire system. Each question has a question number, question sentence, and five alternative answers in a cell. The user selects his answer by tapping the number between 1 and 5 . 5th option means the user strongly agrees with the question sentence. 4th option means the user agrees with that. 3rd option means the user does not agree with but does not disagree with that. 2 nd and 1 st options have the opposite meaning of 4th and 5th options. The score is added to the user score based on the enhanced learning style index, and the total score is also calculated by the index.

\subsection{Teacher Module}

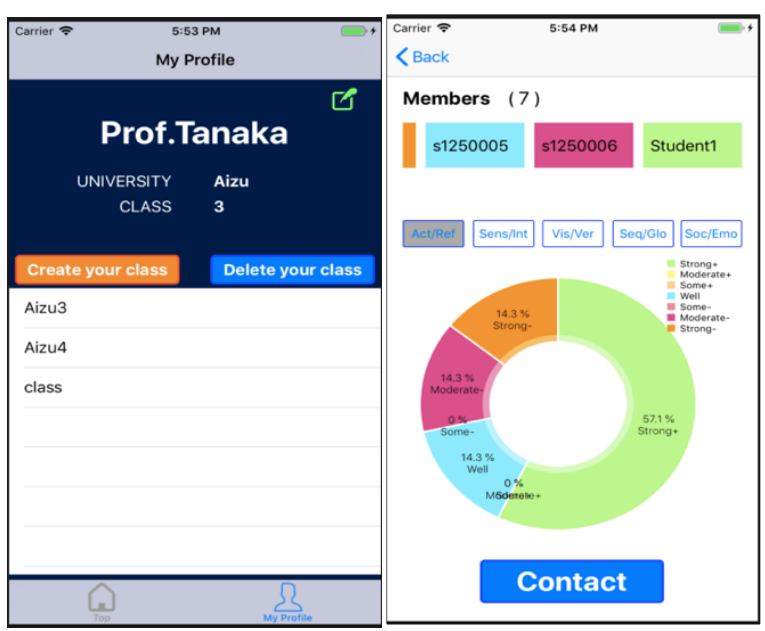

Fig. 5. The views of Teacher Module

The left side of Figure 5 is the view of the user profile when the user whose role is teacher logs in to our system. The view shows the information of the user; name, 
university, and classes which he teaches in. User registers new class to our system and also delete it.

The right side of Figure 5 is the view of analysis for learning styles of students. The graph shows the distribution in each dimension of the learning style model. Users can change the result of dimension by tapping a button above the figure. A teacher can grasp the tendency of learning styles in a class as it is a bird's view.

\section{Discussion and Conclusion}

In this research, we developed an application for analyzing learning styles. The enhanced learning style model is adopted in our system, and it is a relevant model for the questionnaire system. This application is available anywhere on smartphones, and the user will not hesitate to use this application due to the user-friendly interface. For students, they are able to check their learning preferences with ease. Teachers can find out the tendency of learning preferences in their class.

However, if the function of finding more specific learning styles are implemented in our system, the quality of our system will be more increased and more helpful to understand. For example, the system shows users had better study by reading books since the user has "Strong verbal preference" in the Input dimension. We hope our system will be good for every learner.

\section{References}

[1]. Zhang, D., Zhao, J.L., Zhou, L. and Nunamaker Jr, J.F., 2004. Can e-learning replace classroom learning?. Communications of the ACM, 47(5), pp.75-79.

[2]. BankMyCell. 2020. 1 Billion More Phones Than People In The World! Bankmycell. [online] Available at:

$<$ https://www.bankmycell.com/blog/how-manyphones-are-in-the-

world\#: :text=According $\% 20$ to $\% 20$ Statista $\% 2$ $\mathrm{C} \% 20$ the $\% 20$ current, of $\% 20$ that $\% 20$ year's $\% 20 \mathrm{~g}$ lobal\%20population.> [Accessed 7 December 2020].

[3]. 総務省 | 令和元年版 情報通信白書 | 情報通 信機器の保有状況 [online] Available at: $<$ https:/www.soumu.go.jp/johotsusintokei/whit epaper $/ \mathrm{ja} / \mathrm{r} 01 / \mathrm{html} / \mathrm{nd} 232110 . \mathrm{html}>$ [Accessed 7 December 2020].

[4]. Ozuorcun, N.C. and Tabak, F., 2012. Is mlearning versus e-learning or are they supporting each other?. Procedia-Social and Behavioral Sciences, 46, pp.299-305.

[5]. Felder, R.M. and Silverman, L.K., 1988. Learning and teaching styles in engineering education. Engineering education, 78(7), pp.674-681.

[6]. Soloman, B.A. and Felder, R.M., 2005. Index of learning styles questionnaire. NC State University. Available online at: http://www. engr. ncsu. edu/learningstyles/ilsweb. html (last visited on 14.05. 2010), 70.

[7]. Felder, R.M. and Spurlin, J., 2005.

Applications, reliability and validity of the index of learning styles. International journal of engineering education, 21(1), pp.103-112.

[8]. Omar, N., Mohamad, M.M. and Paimin, A.N., 2015. Dimension of learning styles and students' academic achievement. ProcediaSocial and Behavioral Sciences, 204, pp.172182.

[9]. Platsidou, M. and Metallidou, P., 2008. Validity and Reliability Issues of Two Learning Style Inventories in a Greek Sample: Kolb's Learning Style Inventory and Felder \& Soloman's Index of Learning Styles. International Journal of Teaching and Learning in Higher Education, 20(3), pp.324-335.

[10]. Kaliská, L., 2012. Felder's learning style concept and its index of learning style questionnaire in the Slovak conditions. Grant Journal, 1, pp.52-56.

[11]. Hamada, M., Nishikawa, K. and Brine, J., 2013. A study of a learning style index to support an intelligent and adaptive learning systems. In Intelligent and Adaptive Educational-Learning Systems (pp. 109-132). Springer, Berlin, Heidelberg.

[12]. Apple (Latin America). 2020. Iphone. [online] Available at: $<$ https://www.apple.com/lae/iphone/> [Accessed 7 December 2020].

[13]. Apple Developer. 2020. Xcode-Apple Developer. [online] Available at: $<$ https://developer.apple.com/xcode/> [Accessed 7 December 2020].

[14]. Developer.apple.com. 2020. Swift-Apple Developer. [online] Available at: $<$ https://developer.apple.com/swift/> [Accessed 7 December 2020].

[15]. Hamada, M. and Hassan, M., 2017. An enhanced learning style index: implementation and integration into an intelligent and adaptive e-learning system. Eurasia Journal of Mathematics, Science and Technology Education, 13(8), pp.4449-4470. 